\title{
(6) OPEN ACCESS \\ Handover training: does one size fit all? The merits of mass customisation
}

\author{
Wendy Kicken, ${ }^{1}$ Marcel Van der Klink, ${ }^{1}$ Paul Barach, ${ }^{2,3,4}$ HPA Boshuizen ${ }^{1}$
}

\section{- Additional data are published online only. To view these files please visit the journal online (http://dx. doi.org/10.1136/bmjqs- 2012-001164) \\ ${ }^{1}$ Department of Celstec, Centre for Learning Sciences and Technologies, Open University, Heerlen, The Netherlands \\ ${ }^{2}$ Utrecht Medical Center, Utrecht University, Utrecht, The Netherlands \\ ${ }^{3}$ Department of Health Studies, University of Stavanger, Stavanger, Norway \\ ${ }^{4}$ School of Medicine University College Cork, Cork, Ireland}

Correspondence to Wendy Kicken, Department of Celstec, Centre for Learning Sciences and Technologies, Open University, Valkenburgerweg 177, Heerlen 6419 AT, The Netherlands; Wendy.Kicken@ou.nl

Accepted 31 August 2012 Published Online First 29 October 2012

\section{ABSTRACT \\ Background: Experts have recommended training and standardisation as promising approaches to improve handovers and minimise the negative consequences of discontinuity of care. Yet the content and delivery of handover training have been only superficially examined and described in literature.}

Objective: The aim of this study was to formulate recommendations for effective handover training and to examine whether standardisation is a viable approach to training large numbers of healthcare professionals. Methods: A training needs analysis was conducted by means of a questionnaire, which was filled out by 96 healthcare professionals in primary and secondary care in the Netherlands, Spain, Sweden and Poland. Preferences and recommendations regarding training delivery aspects and training topics that should be included in the handover training were measured. Results: The majority of the participants recommended a short conventional training session with practice assignments, to be completed in small, multidisciplinary groups. Formal examination, e-learning and self-study were not favoured. Recommended training topics were: communication skills, standardised procedures, knowing what to hand over, alertness to vulnerable patient groups and awareness of responsibility.

Conclusions: The idea of completely standardised handover training is not in line with the identified differences in preferences and recommendations between different handover stakeholders. Mass customisation of training, in which generic training is adapted to local or individual needs, presents a promising solution to address general and specific needs, while containing the financial and time costs of designing and delivering handover training.

\section{INTRODUCTION}

Patient handover is the transfer of information about and responsibility for a patient between healthcare professionals and settings. This work focuses on patient handovers between the general practitioner or primary care and the hospital or secondary care. Problems with handovers can result in discontinuity of care, which has been implicated in adverse events. ${ }^{2}{ }^{2}$ Experts have emphasised that standardisation of the handover process and improvement of the quality of communication skills and attitudes of healthcare professionals can help to decrease the negative consequences of this discontinuity of care. ${ }^{3-6}$ This requires an effective implementation strategy and an appropriate training to assure effective use of standardised tools, procedures and communication skills. ${ }^{7}$ Often, this training can be standardised, which minimises costs and design efforts.

However, standardised training might undermine the training needs of the trainees and may be less effective than a customised training. ${ }^{8}$ That is, if the content of a standardised training does not match the trainees' training needs, they will be less motivated and willing to engage in the training and have difficulties to transfer what is learned during training to the workplace..$^{9} 10$ The challenge is to design a standardised training that requires only minimal efforts to match trainees' needs. This is called mass customisation. In mass customisation individually designed trainings are based on a generic training design that can easily be customised to each organisation by exchanging some aspects of the training. ${ }^{11}$ Mass customisation of handover training can be a promising approach to develop an effective handover training strategy with little effort and low costs.

To enable mass customisation insight in generic elements of handover training and in stakeholder groups' specific training needs is needed. Unfortunately, although many empirical studies have explored improving patient handovers by means of an educational solution, the literature offers little insight in the actual content and design of the handover, and training delivery aspects are often discussed in a superficial way. ${ }^{1} 4{ }^{12-14}$ This creates a barrier to the 
development of guidelines for effective training in handover. The aim of this study is to formulate recommendations for an effective training in handover, based on a training needs analysis with stakeholders from different European countries. ${ }^{15}$ In addition, it examines to what degree standardisation is a viable solution for effective handover training.

\section{METHODS}

We conducted a training needs analysis to gain more insight in the preferences and needs of various handover stakeholders across Europe. Such an analysis encompasses the examination of the aim, the content, audience and delivery of a handover training programme. In addition, it examines conditions and prerequisites that affect the transfer of training from the training site to the workplace. ${ }^{16-19}$ The analysis of the training needs was conducted by means of a questionnaire.

\section{Study population}

The ninety-six physicians and nurses were selected from primary and secondary care teams in the Netherlands $(\mathrm{n}=23)$, Spain $(\mathrm{n}=28)$, Sweden $(\mathrm{n}=23)$ and Poland $(n=22)$. The clinical focus in these countries was respectively general medical care, cultural minority groups with limited health literacy, emergency services and geriatrics. Participants were included based on their hands-on experience with handovers or involvement in improving handover in their organisation. Sampling was conducted in order to ensure that the study population represented both senior and junior healthcare professionals and an almost equal number of nurses and doctors. The online supplementary table S1 provides an overview of characteristics of the study population.

Prior to the study ethics approval was obtained from the organisations the participants worked. Participants were informed on the aim of the questionnaire and that data would be analysed and presented anonymously.

\section{Training needs analysis questionnaire}

A training needs questionnaire was composed by the authors and piloted with 10 primary and secondary care professionals. After some minor revisions, mainly concerning language issues, the questionnaire was translated into the mother tongue of the participants. Participants were invited personally or via e-mail to complete the questionnaire within 1 week. The questionnaire addressed five topics: satisfaction with current handover practices, suggestions for improvement of handovers, training topics, training delivery and factors influencing the success of training. First participants were asked to indicate whether they were satisfied with the current handover practices in their organisations, then they answered an open-ended question on suggestions for improving handovers.

The third question asked participants to rate the importance of a series of topics for inclusion in handover training: standardised handover procedures; use of tools; communication skills; responsibility; awareness of at-risk patients during handovers; and the information that should be handed over. These topics were derived from a review of studies concerning the facilitators and barriers of effective handover. ${ }^{20}{ }^{21}$ Participants were also invited to mention any other training topic they thought should be part of handover training.

Participants were then asked to make recommendations for the delivery of handover training. Options for the delivery of training were based on the training needs analysis literature. ${ }^{18}$ Participants indicated: (a) whether the duration of the training should be 4 hours, 1 day or 2 days; (b) whether it should be small face-to-face groups, lecture-based, e-learning or learning on the job; (c) whether groups should consist of a single discipline or be multidisciplinary; (d) whether assessment should be informal with practical assignments during training or formal with an examination.

The questionnaire concluded with an open-ended question that asked about factors participants felt would positively affect the success of a training programme, based on their prior experience with training.

\section{Statistical analysis}

The answers to the closed-ended questions were analysed using one-way Analysis of Variance (ANOVA). The question on recommendations for delivery of the training was analysed with descriptive analysis, as it allowed participants to select more than one option. Answers to the open questions were first categorised into themes by one author (WK) using the open sources software Weft QDA. ${ }^{22}$ Next, a member check was conducted by two authors (MVK \& HB) to extract the final set of categories.

\section{RESULTS}

The results are presented first in terms of overall agreement and then in terms of differences between stakeholders groups. In this way it is possible to identify what aspects of a handover training programme could be standardised and what elements should be customised.

\section{Agreement between stakeholders}

Of all participants, $60 \%(\mathrm{n}=58)$ appeared not to be satisfied with the current handover practices in their 
organisations. Suggestions for improvement of handovers frequently mentioned by all participants pertained to (a) improvement of the quality of the information that is handed over, (b) increasing contact between stakeholders of handover, (c) standardisation of handover procedures, and (d) using other artefacts or tools during handover.

The ratings of the suggested potential training topics are presented in the online supplementary table S2. It appears that all participants considered it very important to address the following topics during handover training: (a) alertness to vulnerable patient groups, (b) communication skills, (c) knowing what to hand over, and (d) awareness of being responsible for the patient's wellbeing. The use of tools and standardised procedures were considered slightly less important training topics.

The online supplementary table S3 provides the main findings of the recommendations of the training delivery options. The majority of the participants prefer a training of 4 to $8 \mathrm{~h}$. A longer training duration is not perceived as desirable. Regarding the group of trainees, participants have a strong preference for training in small multidisciplinary groups (8-10 participants). They also indicated a strong preference for conventional training sessions and practical assignments during training, with only a few participants favouring self-study and e-learning. In addition, only a few respondents recommended a formal examination at the completion of training.

Finally, the factors that were perceived to influence the success of a handover training programme could be grouped into five categories: promoting participation, ensuring the transfer of what is learned during training to the workplace, characteristics of the trainer, characteristics of the trainee and the delivery of the training.

The online supplementary table S4 provides an overview of these categories and an example for each category.

\section{Differences between stakeholders}

It appeared that a higher number of participants who work in primary care mention to be less satisfied (78\% of the nurses, $n=21 ; 67 \%$ of the doctors, $n=14$ ) with the current handover practices in their organisation, than their colleagues in secondary care $(50 \%$ of the nurses, $\mathrm{n}=12 ; 46 \%$ of the doctors, $\mathrm{n}=11$ ). On country level, more than half of the Spanish participants $(57 \%, \mathrm{n}=16)$ were satisfied with the current handover practices, whereas only a small number of participants from the Netherlands (30\%, $\mathrm{n}=7)$, Sweden $(35 \%, \mathrm{n}=8)$ and Poland $(32 \%, \mathrm{n}=7)$ were satisfied.

The suggestions for improving handover practices also demonstrate some differences between countries. It appeared that participants in each country mention handover training topics, not mentioned by participants from other countries. The Dutch healthcare professionals frequently suggested reducing the time interval between the discharge and receiving the discharge letter or any feedback from the secondary care provider. Polish healthcare professionals proposed to tackle the problem of receiving incomplete or no information at all after referrals or discharges. Finally, the Swedish and Spanish healthcare professionals both emphasised the need for standardised procedures and the use of compatible, improved information systems.

Moreover, the ratings of potential training topics showed some country-specific patterns. The Dutch participants perceived training in the use of tools significantly less important than the participants from the other countries $(\mathrm{F}=12.8, \mathrm{MSe}=3.78, \mathrm{p}=0.000)$. In addition, the Polish participants found it significantly less important to train what kind of information should be handed over, than the participants from Sweden or Spain $(\mathrm{F}=4.2$, MSe $=0.90, \mathrm{p}=0.000)$. No differences were found between the ratings of potential training topics by the different healthcare professionals. However, healthcare professionals differed in the additional training topics they suggested to include in handover training. Primary and secondary care nurses stressed the importance of making trainees more aware of multidisciplinary responsibility for the patient. In addition, they recommend training to improve relations between handover stakeholders, including encouraging trainees to put oneself in someone else's position when handing information over. The primary and secondary care doctors, on the other hand, suggested that training should focus on increasing the speed of handover and on summarising information for handover in a structured and concise manner.

With respect to recommendations for the training delivery, online supplementary table S3 shows that participants from different countries differ in their recommendations and preferences. The Dutch participants recommended to limit training duration to one day maximum and a slightly higher percentage of Dutch participants favoured self-study or e-learning than participants from the other three countries (see online supplementary table S3: $39 \% \mathrm{n}=9$ vs $5 \% \mathrm{n}=1,27 \% \mathrm{n}=6$, and $14 \% \mathrm{n}=4)$. The highest percentage of care professionals that perceived learning on the job as desirable was found in Spain $(96 \%, n=27)$. A formal examination was not favoured at all by the Polish care professionals, whereas Swedish professionals $(43 \%, \mathrm{n}=10)$ favoured a formal examination in order to assess competency. Differences between healthcare professionals were only found for self-study or e-learning which was favoured more by primary care doctors $(43 \%, \mathrm{n}=9)$ than by the other professionals $(8-19 \%, \mathrm{n}=2-5)$. 
Finally, no striking differences were found regarding the factors mentioned to influence the success of a handover training programme.

\section{DISCUSSION}

The training needs analysis conducted in this study has provided more insight in the preferences of a diverse group of health care professionals regarding handover training. It is striking to find that many health care professionals, especially those in primary care, are dissatisfied with current handover practices in their organisations. Participants also offered suggestions for improvement that could be part of a customised handover training programme. Most suggestions pertained to improving the quality and frequency of communication (ie, more and better communication), standardising handover procedures, and using other and better tools. These suggestions are in line with suggested handover training topics reported in the literature. ${ }^{14} 2021$ It is noteworthy that, when asked to indicate important training topics, participants rated training on of standardised handover protocols or use of tools less important than topics like alertness to vulnerable patient groups, awareness of responsibility, communication skills and knowing what information to hand over. Apparently, participants are aware of topics beyond the standardisation of procedures, particularly awareness of circumstances of the handover (such as vulnerable populations), handover content, and how to hand over information.

Regarding the delivery of the training it was recommended by the majority of the participants to provide conventional training sessions with practical assignments for small, multidisciplinary groups. The recommendations reflect the current common approach for delivering a training programme, except for the recommendation that training to be conducted in multidisciplinary groups. Apparently participants find it important to train with colleagues to whom they will hand over the patient.

Besides these areas of agreement among the diverse group of stakeholders, we found some differences in training needs and preferences. This suggests that, although it is possible to standardise some training topics and elements of delivery, customisation is needed also to take into consideration trainees' needs and preferences, to optimise the effectiveness of training. For example, it appeared that secondary care professionals are more satisfied with the current quality of handover practices than their colleagues in primary care. As a consequence, it may be more difficult to convince secondary care professionals to participate in handover training, because they may not perceive it as necessary. Promotion of participation in training, one of the factors for successful training, should therefore focus specifically on this group.
In addition, customisation is necessary to take into account the diversity of experienced handover problems and suggested solutions to these problems. This makes the training more relevant, and ensures the transfer of training, indicated by the participants as an important factor for success. This means that besides common, standardised topics (eg, communication skills, knowing what to handover over, awareness and alertness), training should include topics based on handover problems experienced in the given professional group or setting, and relevant solutions to these problems. Customisable topics for the study populations included putting oneself into someone the position of the recipient of the information (suggested by nurses), increasing the speed of handover (suggested by physicians). It is also possible to customise a training programme by emphasising certain topics more than others or to use different instructions, assignments or examples. For example when discussing the topic 'handover procedure' trainees in Poland will be trained to always hand over information after discharge, whereas Dutch trainees, who already have developed these skills, will be educated on how to reduce the time between discharge and sending the discharge letter. These customised topics can be deduced from a training needs analysis that is conducted prior to training.

Our study has three limitations that need to be taken into account when interpreting the data. First, the small number of participants limited more advanced analysis, and it was not possible to compare the preferences and recommendations between different groups of professionals within a country. However, the study population is a purposeful sample, showing that even in the four countries participating in the study differences in handover problems and solutions to these problems exist, which led to different needs for training. Second, the data was collected only by means of a questionnaire. Though a questionnaire is a well-accepted, cost-effective method its disadvantage lies in its limited contribution to in-depth insights. By adding open questions that invited participants to express their opinions and suggestions in a free-text format this disadvantage was partly countered. Third, the current study only provides recommendations for effective handover training based on opinions of trainees and does not measure the effectiveness of these recommendations. Future studies should investigate whether implementation of these suggestions would translate to more effective handover training and improved patient handovers.

\section{CONCLUSIONS}

Although standardisation of handover training seems to be an intuitive solution to handovers problems, a 
training needs analysis shows that one size does not fit all. Therefore, providing a completely standardised handover training programme may not be the most effective approach to improve handovers.

A more promising approach that matches the findings of the needs analysis might be mass customisation. In this case, the handover training has both basic or generic training topics and delivery aspects and flexible or customisable elements. Customisation is based on the results of a training needs analysis that reveals the experienced needs of trainees or an organisation. Based on the findings of our study, standardised elements of handover training and delivery include a short conventional training conducted in small multidisciplinary groups, focus on healthcare professionals' awareness of their responsibility, knowing what to hand over and how (ie, communication skills) and alertness to vulnerable patient groups who may be at-risk during handovers. Customisable aspects of training content and delivery derived from our findings include use of e-learning, assessment via a formal examination; focus on speed of handovers; and emphasising the importance of consistently handing over all patient information.

Acknowledgements We thank all the members of the European HANDOVER Research Collaborative for their participation in this study. Slavi Stoyanov, Hendrik Drachsler, Loes Pijnenborg, Julie Johnson, Beryl Göbel, Cor Kalkman, Richard Lilford, Nicola Novielli, Yen-Fu Chen, Semira Manaseki-Holland, Basia Kutryba, Halina Kutaj-Wasikowska, Ewa Dudzik-Urbaniak, Marcin Kalinowski, Francesco Venneri, Giulio Toccafondi, Antonio Molisso, Sara Albolino, Hub Wollersheim, Gijs Hesselink, Lisette Schoonhoven, Myrra Vernooij, Marieke Zegers, Helen Hansagi, Mariann Olsson, Susanne Bergenbrant, Maria Flink, Gunnar Ohlen, Carola Orrego, Rosa Sunol, Oliver Groene.

Contributors WK: substantial contributions to conception and design, acquisition of data, analysis and interpretation of data; drafting the article (all sections), revising it critically; and final approval of the version to be published. M K: substantial contributions to conception and design, acquisition of data, analysis and interpretation of data; drafting the article (background and discussion), revising it critically; and final approval of the version to be published.

Funding This study was supported by a grant from the European Union, the Framework Programme of the European Commission (FP7-HEALTH-F2-2008223409). The study sponsor had no role in the study design; collection, analysis, and interpretation of the data; or in the writing of the article and decision to submit the article for publication.

Competing interests None.

Ethics approval Prior to the study ethics approval was obtained from the organizations the participants worked. Participants were informed on the aim of the questionnaire and that data would be analysed anonymously.

Provenance and peer review Not commissioned; externally peer reviewed

Open Access This is an Open Access article distributed in accordance with the Creative Commons Attribution Non Commercial (CC BY-NC 3.0) license, which permits others to distribute, remix, adapt, build upon this work non-

commercially, and license their derivative works on different terms, provided the original work is properly cited and the use is non-commercial. See: http:// creativecommons.org/licenses/by-nc/3.0/

\section{REFERENCES}

1. Kohn LT, Corrigan JM, Donaldson S. To err is human, building a safer health system. Washington, DC: National academy press, 1999.

2. Simpson K. Handling handoffs safely. Am J Matern Child Nurs 2005;30:152.

3. Barach P, Johnson JK. Understanding the complexity of redesigning care around the clinical microsystem. Qual Saf Health Care 2006;15 (Suppl I):10-6.

4. Francke AL, Smit MC, de Veer JF, et al. Factors influencing the implementation of clinical guidelines for health care professionals: a meta-review. BMC, Med Inform Decis Mak 2008;8:38.

5. Sutcliffe K, Lewton E, Rosenthal MM. Communication failures: An insidious contributor to medical mishaps. Acad Med 2004;79:186-94.

6. Perrow C. Normal accidents: living with high-risk technologies. Princeton, NJ: Princeton University Press, 1999.

7. Safe Handover: Safe Patients - Guidance on Clinical Handover for Clinicians and Managers. Australian Medical Association 2006.http:// www.ama.com.au/web.nsf/doc/WEEN6XFDSP/\$file/ Clinical_Handover.pdf

8. Robinson DG, Robinson JC. Training for impact. How to link training to business needs and measure the results. San Francisco: Jossey-Bass, 1989.

9. Kauffman RJ, Tsai JY. With or without you: the countervailing forces and effects of process standardization. Electron Commer Res Appl 2010;9:305-22.

10. Ryan RM, Deci EL. Self-determination theory and the facilitation of intrinsic motivation, social development, and well-being. Am. Psychol 2000;55:68-78.

11. Da Silveira G, Borenstein D, Fogliatto SF. Mass customization literature review and research directions. Int J Prod Econom 2001;72:1-13.

12. Arora V, Johnson JK, Meltzer DO, et al. A theoretical framework and competency-based approach to improving handoffs. Qual Saf Health Care 2008;17:11-4.

13. Shojania KG, Fletcher KE, Sanjay S. Graduate medical education and patient safety: a busy and occasionally hazardous intersection Ann. Intern. Med. 2006;145:592-8.

14. Gordon M, Findley R. Educational interventions to improve handover in health care: a systematic review. Med Educ 2011;45:1081-9. doi:10.1111/j.1365-2923.2011.04049.

15. Van Kemenade YW. Healthcare in Europe. Amsterdam The Netherlands: Reed business, 2007.

16. Kuniavsky M. Observing the user experience-a practitioner's guide to user research. San Francisco: Morgan Kaufmann Publishers Inc, 2003.

17. Dierdorff EC, Surface EA. Assessing training needs: do work experience and capability matter? Hum Perform 2008;21:28-48.

18. Rosset A. Training needs assessment. Englewood Cliffs, NJ: Educational Technology Publications, 1987.

19. Kicken W, Van der Klink M, Stoyanov S, et al. Report on training needs and appropriation guideline per region and category. http:// handover.cmj.org.pl/upload/library/m1b8hmo6d0hh9fiybvx8w.pdf

20. Cohen MD, Hilligoss PB. Handoffs in Hospitals: A review of the literature on information exchange while transferring patient responsibility or control 2009. http://deepblue.lib.umich.edu/bitstream/ 2027.42/61522/1/Handoffs in Hospitals_Draft_2009 01 28.pdf

21. Mistiaen P. Hospital discharge: problems and interventions. Unpublished doctoral dissertation. Maastricht, The Netherlands: Maastricht University 2007.

22. Fenton A. Weft QDA (Computer software) 2006 